\title{
Free Vibration Analysis of Beams Considering Different Geometric Characteristics and Boundary Conditions
}

\author{
Mehmet Avcar \\ Civil Engineering Department, Engineering Faculty, Suleyman Demirel University, Isparta, Turkey
}

\begin{abstract}
In this study, free vibration of square cross-sectioned aluminum beams is investigated analytically and numerically under four different boundary conditions: Clamped-Clamped (C-C), Clamped-Free (C-F), Clamped-Simply Supported (C-SS) and Simply Supported-Simply Supported (SS-SS). Analytical solution is carried out using Euler-Bernoulli beam theory and Newton Raphson Method. First, the equations of motion are provided. Then, solutions including the effects of the geometric characteristics, and boundary conditions are obtained and discussed for the natural frequencies of the first three modes. To confirm the reliability of the vibration analysis carried out in the present paper as well, all the analytical results are checked with the corresponding numerical results obtained from the finite-element-method (FEM) based software called ANSYS. Numerical and analytical results are found to be good agreement.
\end{abstract}

Keywords Free Vibration, Beam, Natural Frequency, Boundary Conditions, Geometric Characteristics

\section{Introduction}

A beam is a slender horizontal structural member that resists lateral loads by bending, and this important element of engineering structures appears in various forms and comprises various artifacts, such as supporting members in high-rise buildings, railways, long-span bridges, flexible satellites, gun barrels, robot arms, airplane wings, etc. [1, 2].

In many engineering applications, beams are subjected to dynamic loads, which can excite beam structural vibrations and cause durability concerns or discomfort because of the resulting noise and vibration. In addition, if the vibration exceeds certain limits, there is the danger of beam breakage or failure [3-6].

Due to beams are important structural elements, vibration analysis has been a vital task in their design for engineers and researchers for more than a century. Early investigations of the theory of vibration were given in Refs [7-9]. Then an increasing interest has been observed regarding the vibration of beams, and several studies have appeared in the general literature, some of which are provided in the Refs [10-25].

In this study, the free vibration of square cross-sectioned aluminum beams is investigated analytically and numerically under four different boundary conditions. Analytical solution is carried out using Euler-Bernoulli beam theory, in which material is assumed to be linear-isotropic, and Newton Raphson Method. This method is based on the

* Corresponding author:

mehmetavcar@sdu.edu.tr (Mehmet Avcar)

Published online at http://journal.sapub.org/mechanics

Copyright (C 2014 Scientific \& Academic Publishing. All Rights Reserved simple idea of linear approximation, and used for finding the roots of equations. It is particularly useful for transcendental equations, composed of mixed trigonometric and hyperbolic terms. Such equations occur in vibration analysis. An example is the calculation of natural frequencies of continuous structures [26]. Solutions including the effects of the geometric characteristics, i.e., length and cross sectional area, and boundary conditions are obtained and discussed for the natural frequencies of the first three modes. Furthermore, to confirm the reliability of the vibration analysis carried out in the present paper as well, all the analytical results are checked with the corresponding numerical results obtained from Finite Element Method (FEM)-based software called ANSYS [27], where the method is established on the idea of building a complicated object with simple blocks, or, dividing a complicated object into smaller and manageable pieces [28].

Present analysis can be used as a comparative study or data for the different solution methods of future works in the related field.

\section{Basic Equations}

Consider an elastic beam of length $L$, Young's modulus $E$, and mass density $\rho$ with uniform cross section $A$, as shown in Figure 1.

Using Euler-Bernoulli beam theory, one can obtain the equation of motion of a beam with homogeneous material properties and constant cross section as follows [5]:

$$
E I \frac{\partial^{4} w}{\partial x^{4}}+\rho A \frac{\partial^{2} w}{\partial t^{2}}=0 ; \quad 0 \leq x \leq L
$$


where $I$ is the area moment of inertia of the beam cross section, $w$ is the transverse displacement, and $\mathrm{t}$ is time.

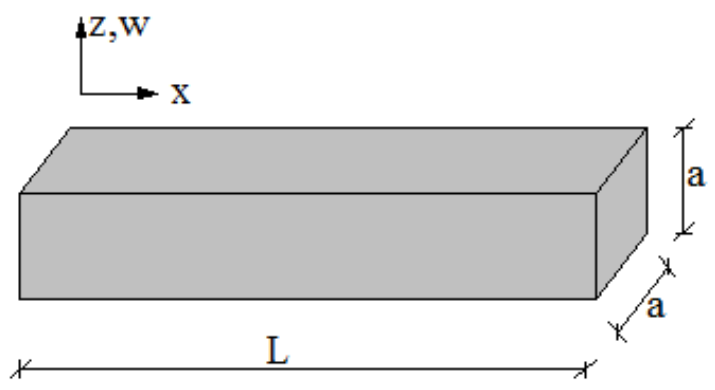

Figure 1. Geometry of the beam

Eq. (1) can be rearranged as follows:

$$
E I \frac{\partial^{4} w}{\partial x^{4}}+\kappa \frac{\partial^{2} w}{\partial t^{2}}=0
$$

where $\kappa=\rho A$ is the linear mass density of the beam.

The solution of the Eq. (2) is sought by separation of variables. Assume that the displacement can be separated into two parts: one is depending on the position and the other is depending on time, as follows:

$$
w(x, t)=\Lambda(x) \Psi(t)
$$

where $\Lambda$ and $\Psi$ are independent of time and position, respectively.

Substituting Eq. (3) into Eq. (2) and after some mathematical rearrangements, the following equation is obtained:

$$
-\frac{E I}{\kappa \Lambda(x)} \frac{\partial^{4} \Lambda(x)}{\partial x^{4}}=\frac{1}{\Psi(t)} \frac{\partial^{2} \Psi(t)}{\partial t^{2}}
$$

As observed from Eq. (4), the left side depends on the variable $\mathrm{x}$, and the right side depends on the variable $\mathrm{t}$, as previously noted. Consequently, the variables have been separated, and each side of (4) must equal a constant, denoted $-\omega^{2}$ to have simple harmonic motion in the system.

$$
-\frac{E I}{\kappa \Lambda(x)} \frac{\partial^{4} \Lambda(x)}{\partial x^{4}}=\frac{1}{\Psi(t)} \frac{\partial^{2} \Psi(t)}{\partial t^{2}}=-\omega^{2}
$$

If the position variable is separated

$$
\frac{\partial^{4} \Lambda(x)}{\partial x^{4}}-\delta^{4} \Lambda(x)=0
$$

where

$$
\delta^{4}=\omega^{2} \frac{\kappa}{E I}
$$

If the time variable is separated

$$
\frac{\partial^{2} \Psi(t)}{\partial t^{2}}+\omega^{2} \Psi(t)=0
$$

Eq. (6) is solved as follows:

$$
\begin{aligned}
\Lambda(x)= & C_{1} \sinh \delta x+C_{2} \cosh \delta x+C_{3} \sin \delta x \\
& +C_{4} \cos \delta x
\end{aligned}
$$

where $C_{1}, \ldots, C_{4}$ are constants, and $\sinh$ and cosh are the hyperbolic $\sin e$ and $\cos e$ functions, respectively.

Eq. (8) is solved as follows:

$$
\Psi(t)=C_{5} \sin \omega t+C_{6} \cos \omega t
$$

where $C_{5}$ and $C_{6}$ are constants.

Thus, if Eq. (9) is multiplied by Eq. (10) to obtain $w(x, t)$, it yields eight combined constants as:

$$
\begin{aligned}
& w(x, t) \\
= & \left(C_{1} \sinh \delta x+C_{2} \cosh \delta x+C_{3} \sin \delta x+C_{4} \cos \delta x\right) \\
& \times\left(C_{5} \sin \omega t+C_{6} \cos \omega t\right)
\end{aligned}
$$

where the constants $C_{1}, C_{2}, C_{3}, C_{4}$ can be obtained from the boundary conditions, and $C_{5}, C_{6}$ can be obtained from the initial conditions

Finally, using Eq. (7) the natural frequency $f_{n}(\mathrm{~Hz})$ of the beam is found as follows:

$$
f_{n}=\frac{\omega}{2 \pi}
$$

\section{Solution of the Basic Equations}

\subsection{Particular Solution for C-C Beam}

The boundary conditions satisfied by a $\mathrm{C}-\mathrm{C}$ beam are as follows:

$$
\begin{aligned}
& \left.w\right|_{x=0}=0 \text { and }\left.\frac{\partial w}{\partial x}\right|_{x=0}=0 \\
& \left.w\right|_{x=L}=0 \text { and }\left.\frac{\partial w}{\partial x}\right|_{x=L}=0
\end{aligned}
$$

When Eqs. (13)-(14) are considered in Eq. (9), after some mathematical operations, the coefficient matrix is obtained as follows:

$$
\left[\begin{array}{cc}
\sinh \delta L-\sin \delta L & \cosh \delta L-\cos \delta L \\
\cosh \delta L-\cos \delta L & \sinh \delta L+\sin \delta L
\end{array}\right]\left[\begin{array}{l}
C_{1} \\
C_{2}
\end{array}\right]=\left[\begin{array}{l}
0 \\
0
\end{array}\right]
$$

The non-trivial solution of the determinant of the coefficient matrix is as follows:

$$
\cos \delta_{n} \cosh \delta_{n} L=1
$$

where the subscript is an integer index. 
Because the first three roots of Eq. (16) are calculated using the Newton-Raphson method, the following eigenvalues are obtained:

$$
\begin{aligned}
& \delta L=4.73004 \text { for } n=1 \\
& \delta L=7.85321 \text { for } n=2 \\
& \delta L=10.9956 \text { for } n=3
\end{aligned}
$$

where, $\delta \mathrm{L}$, is the natural frequency parameter of the beam.

\subsection{Particular Solution for C-F Beam}

The boundary conditions satisfied by a C-F beam are as follows:

$$
\begin{gathered}
\left.w\right|_{x=0}=0 \text { and }\left.\frac{\partial w}{\partial x}\right|_{x=0}=0 \\
\left.\frac{\partial^{2} w}{\partial x^{2}}\right|_{x=L}=0 \text { and }\left.\frac{\partial^{3} w}{\partial x^{3}}\right|_{x=L}=0
\end{gathered}
$$

When Eqs. (18)-(19) are considered in Eq. (9), after some mathematical rearrangements, the following coefficient matrix is obtained:

$$
\left[\begin{array}{cc}
\sinh \delta L+\sin \delta L & \cosh \delta L+\cos \delta L \\
\cosh \delta L+\cos \delta L & \sinh \delta L-\sin \delta L
\end{array}\right]\left[\begin{array}{l}
C_{1} \\
C_{2}
\end{array}\right]=\left[\begin{array}{l}
0 \\
0
\end{array}\right]
$$

The non-trivial solution of the determinant of the coefficient matrix is as follows:

$$
\cos \delta_{n} L \cosh \delta_{n} L=-1
$$

When the first three roots of Eq. (21) are calculated using Newton-Raphson method, the following eigenvalues are obtained:

$$
\begin{aligned}
& \delta L=1.87510 \text { for } n=1 \\
& \delta L=4.69409 \text { for } n=2 \\
& \delta L=7.85340 \text { for } n=3
\end{aligned}
$$

\subsection{Particular Solution for C-SS Beam}

The boundary conditions satisfied by a C-SS beam are as follows:

$$
\left.w\right|_{x=0}=0 \text { and }\left.\frac{\partial w}{\partial x}\right|_{x=0}=0
$$

$$
\left.w\right|_{x=L}=0 \text { and }\left.\frac{\partial^{2} w}{\partial x^{2}}\right|_{x=L}=0
$$

When Eqs. (23)-(24) are considered in Eq. (9), after some mathematical rearrangements, the following coefficient matrix is obtained:

$$
\left[\begin{array}{cc}
\sinh \delta L-\sin \delta L & \cosh \delta L-\cos \delta L \\
\sinh \delta L+\sin \delta L & \cosh \delta L+\cos \delta L
\end{array}\right]\left[\begin{array}{l}
C_{1} \\
C_{2}
\end{array}\right]=\left[\begin{array}{l}
0 \\
0
\end{array}\right]
$$

The solution of the determinant of the coefficient matrix is as follows:

$$
\tanh \delta_{n} L=\tan \delta_{n} L
$$

Because the first three roots of Eq. (26) are calculated using Newton-Raphson method, the following eigenvalues are obtained:

$$
\begin{aligned}
& \delta L=3.9266 \text { for } n=1 \\
& \delta L=7.0686 \text { for } n=2 \\
& \delta L=10.2102 \text { for } n=3
\end{aligned}
$$

\subsection{Particular Solution for SS-SS Beam}

The boundary conditions satisfied by a SS-SS beam are as follows:

$$
\begin{gathered}
\left.w\right|_{x=0}=0 \text { and }\left.\frac{\partial^{2} w}{\partial x^{2}}\right|_{x=0}=0 \\
\left.w\right|_{x=L}=0 \text { and }\left.\frac{\partial^{2} w}{\partial x^{2}}\right|_{x=L}=0
\end{gathered}
$$

When Eqs. (28)-(29) are considered in Eq. (9), after some mathematical rearrangements, the following coefficient matrix is obtained:

$$
\left[\begin{array}{ll}
\sinh \delta L & \sin \delta L \\
\sinh \delta L & -\sin \delta L
\end{array}\right]\left[\begin{array}{l}
C_{1} \\
C_{3}
\end{array}\right]=\left[\begin{array}{l}
0 \\
0
\end{array}\right]
$$

The non-trivial solution of the determinant of the coefficient matrix is as follows:

$$
\sin \delta_{n} \sinh \delta_{n} L=0
$$

Because the first three roots of Eq. (31) are calculated using Newton-Raphson method, the following eigenvalues are obtained: 


$$
\begin{aligned}
& \delta L=3.1415 \text { for } n=1 \\
& \delta L=6.2832 \text { for } n=2 \\
& \delta L=9.4248 \text { for } n=3
\end{aligned}
$$

\section{Numerical Results and Discussion}

\subsection{Comparative Study}

In this subsection, a comparative study was performed to validate the present numerical results. The analytical results were compared with the results of the FEM -based software called ANSYS [27]. In finite-element modeling, the beam type element is applied and meshed with 50 elements.

For the first three modes $n=1 ; 2 ; 3$, the analytical natural frequencies, $f_{\text {nAnaly }}(\mathrm{Hz})$, and the FEM natural frequencies, $f_{\text {nFEM }}(\mathrm{Hz})$, differ by $0.223 \%, 0.842 \%$, and $1.782 \%$ under C-C boundary conditions, $0.083 \%$, $0.592 \%$, and $1.381 \%$ under C-F boundary conditions, $0.213 \%, \quad 0.784 \%$, and $1.698 \%$ under C-SS boundary conditions, and $0.183 \%, 0.722 \%$, and $1.605 \%$ under SS-SS boundary conditions, respectively. The percentages are calculated as follows: $\left(\frac{f_{\text {nAnaly }}-f_{\text {nFEM }}}{f_{\text {nAnaly }}}\right) \times 100$. As shown in Figure 2, the numerical results of both methods are consistent, which shows the accuracy of the present formulation.

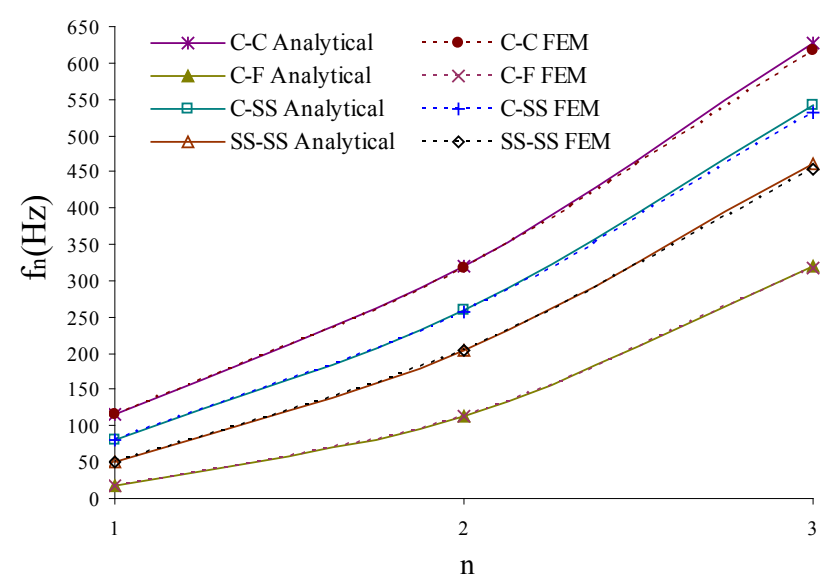

Figure 2. Comparisons between the analytical natural frequencies and those obtained using FEM -based software called ANSYS versus mode number, $\mathrm{n}\left(E=70 \times 10^{9} \mathrm{~N} / \mathrm{m}^{2} ; \rho=2700 \mathrm{~kg} / \mathrm{m}^{3} ; \mathrm{L}=3 \mathrm{~m}\right.$; $\left.\mathrm{A}=0.04 \mathrm{~m}^{2}\right)$

\subsection{Free Vibration Analyses of Beams}

In this section, four studies were performed to investigate the free-vibration behaviors of square cross-sectioned aluminum beams with different geometric characteristics under four different boundary conditions. The natural frequencies were obtained and discussed for the first three modes $(\mathrm{n}=1,2,3)$, including the effects of the geometric characteristics, i.e., length and cross sectional area, and the boundary conditions.

\section{Study 1:}

In Figure 3, the variations in natural frequencies, $f_{n}(\mathrm{~Hz})$, of square cross-sectioned aluminum beams versus the first three modes $(n=1,2,3)$ under four different cross sections are plotted, where A1;A2; A3 denote $\mathrm{A}=0.0225 \mathrm{~m}^{2} ; 0.04 \mathrm{~m}^{2} ; 0.0625 \mathrm{~m}^{2}$, and $\mathrm{L} 1 ; \mathrm{L} 2 ; \mathrm{L} 3$ denote $\mathrm{L}=2.75 \mathrm{~m} ; 3 \mathrm{~m} ; 3.25 \mathrm{~m}$, respectively. Figure 3 shows that the natural frequencies increase with the increase in mode number. The natural frequency of the first mode number $(n=1)$ differs from that of the second and third mode numbers $(n=2,3)$ by $-176 \%$ and $-440 \%$ under the C-C boundary conditions, $-527 \%$ and $-1654 \%$ under C-F boundary conditions, $-224 \%$ and $-576 \%$ under C-SS boundary conditions, and $-300 \%$ and $-800 \%$ under SS-SS boundary conditions, respectively. The percentages were calculated as follows: $\left(\frac{f_{n 1}-f_{n i}}{f_{n 1}}\right) \times 100 ;(i=2,3)$. Therefore, the variation in mode number has the largest effect on the natural frequency under C-F boundary conditions and the smallest effect under $\mathrm{C}-\mathrm{C}$ boundary conditions.

\section{Study 2:}

Figure 3 shows that the beam has the highest natural frequencies, $f_{n}(\mathrm{~Hz})$, under $\mathrm{C}-\mathrm{C}$ boundary conditions and the lowest frequencies under $\mathrm{C}-\mathrm{F}$ boundary conditions. To investigate the effect of the boundary condition on the natural frequencies, $f_{n}(\mathrm{~Hz})$, of the beam versus the mode number, $(\mathrm{n}=1,2,3)$, the $\mathrm{C}-\mathrm{C}$ boundary conditions were compared with the other boundary conditions. From this comparison, the following results were obtained: for $\mathrm{n}=1,2$, and 3, i) the differences between C-C and C-F boundary conditions are $84 \%, 64 \%$, and $49 \%$, ii) the differences between C-C and C-SS boundary conditions are $31 \%, 19 \%$, and $14 \%$, and iii) the differences between C-C and SS-SS boundary conditions are $56 \%, 36 \%$, and $27 \%$, respectively. The percentages were calculated as follows: $\left(\frac{f_{n C-C}-f_{n i}}{f_{n C-C}}\right) \times 100 ;(i=C-F ; C-S S ; S S-S S)$ Therefore, the effect of the type of the boundary condition decreases with the increase in mode number, $n$. 


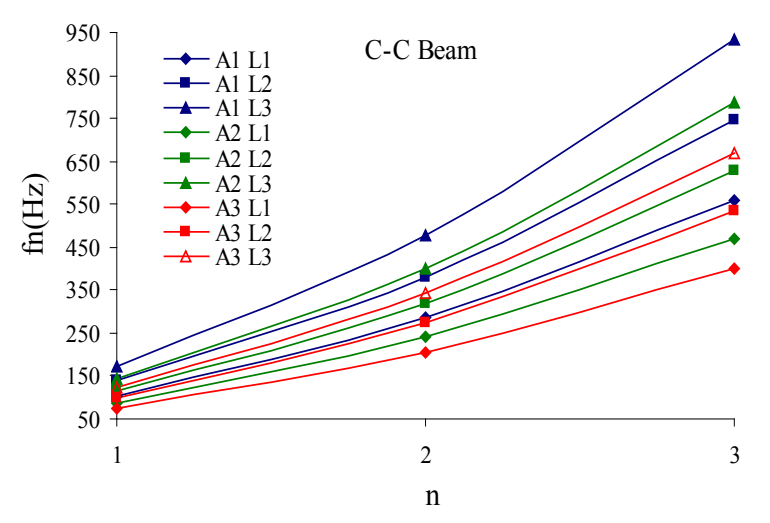

a)

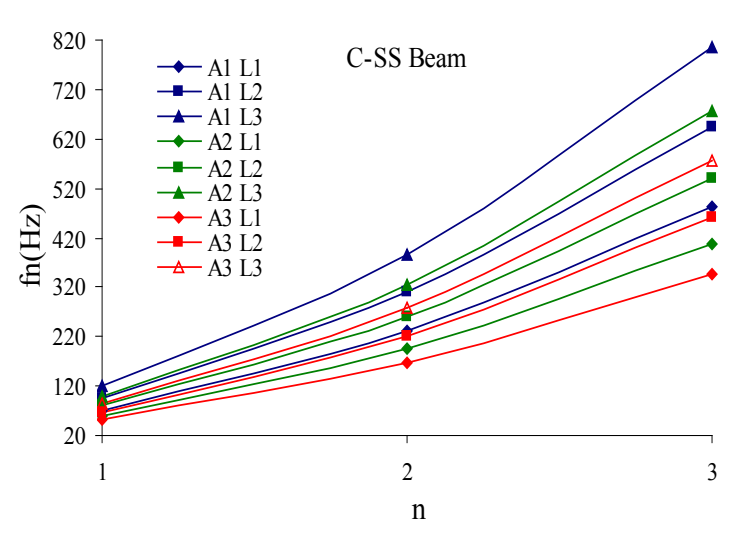

c)

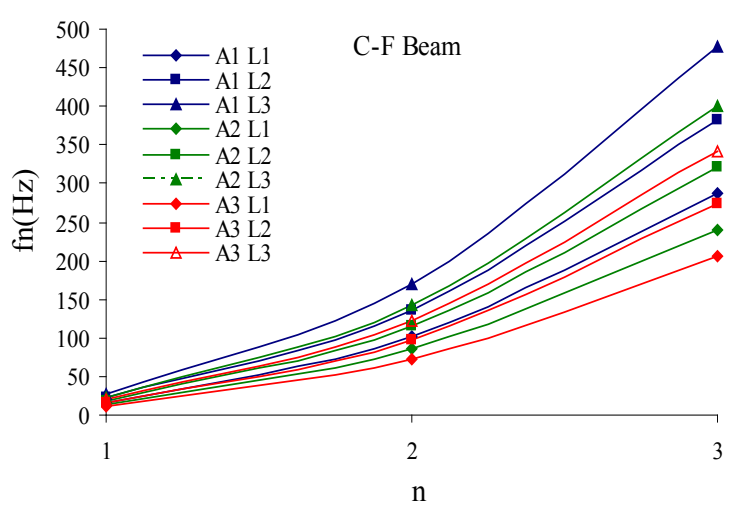

b)

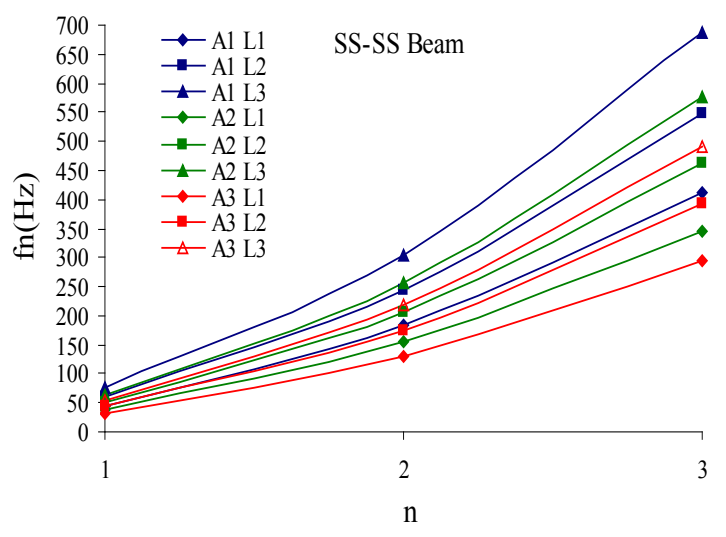

d)

Figure 3. Variations of the natural frequencies, $f_{n}(H z)$, of square cross-sectioned aluminum beams for the first three modes, $(\mathrm{n}=1,2,3)$ $\left(E=70 \times 10^{9} \mathrm{~N} / \mathrm{m}^{2} ; \rho=2700 \mathrm{~kg} / \mathrm{m}^{3}\right)$

\section{Study 3:}

Figure 4 shows the variations in natural frequency, $f_{n}(\mathrm{~Hz})$, of square cross-sectioned aluminum beams versus the length, $\mathrm{L}(\mathrm{m})$, under four different boundary conditions, where $\mathrm{A} 1 ; \mathrm{A} 2 ; \mathrm{A} 3$ denotes $\mathrm{A}=0.0225 \mathrm{~m}^{2}$; $0.04 \mathrm{~m}^{2} ; 0.0625 \mathrm{~m}^{2}$, and $\mathrm{n} 1 ; \mathrm{n} 2 ; \mathrm{n} 3$ denote $\mathrm{n}=1 ; 2 ; 3$, respectively. Figure 4 obviously shows that the natural frequencies, $f_{n}(\mathrm{~Hz})$, decrease with the increase in length, $\mathrm{L}(\mathrm{m})$. To examine the effect of the variation in length of the beam on the natural frequencies, beams with identical cross sectional areas were compared. The result indicated that the variation in length had a constant effect on the natural frequencies: $15.97 \%$ and $28.40 \%$ for all cross sectional areas $\left(\mathrm{A}=0.0225 \mathrm{~m}^{2} ; 0.04 \mathrm{~m}^{2} ; 0.0625 \mathrm{~m}^{2}\right)$ under four different boundary conditions. The percentages were calculated as follows: $\left(\frac{f_{n L=2.75}-f_{L i}}{f_{n L=2.75}}\right) \times 100 ; \quad(i=3,3.25)$. Thus, the change in length of the beam has a constant effect on its natural frequencies for various boundary conditions and cross sectional areas.

\section{Study 4:}

Figue 5 shows the variations in natural frequencies of square cross-sectioned aluminum beams versus the cross sectional area, $\mathrm{A}\left(\mathrm{m}^{2}\right)$, under four different cross sections, where $\mathrm{L} 1 ; \mathrm{L} 2 ; \mathrm{L} 3$ denote $\mathrm{L}=2.75 \mathrm{~m} ; 3 \mathrm{~m} ; 3.25 \mathrm{~m}$, and $\mathrm{n} 1 ; \mathrm{n} 2 ; \mathrm{n} 3$ denote $\mathrm{n}=1 ; 2 ; 3$, respectively. Figure 5 shows that the natural frequencies increase with the increase in cross sectional area. To investigate the effect of the variation in cross sectional area of the beam on the natural frequencies, beams with identical lengths were compared. The result indicated that variation of the cross sectional area had a constant effect on the natural frequencies: $-33.33 \%$ and $-66.67 \%$ for $L=2.75 \mathrm{~m} ; 3 \mathrm{~m} ; 3.25 \mathrm{~m}$ under four different boundary conditions. The percentages were calculated as follows: $\left(\frac{f_{n A=0.0225}-f_{A i}}{f_{n A=0.0225}}\right) \times 100$; $(i=0.04,0.0625)$. Thus, the change in cross sectional area of the beam has a constant effect on the natural frequencies of the beam for various boundary conditions and lengths. 


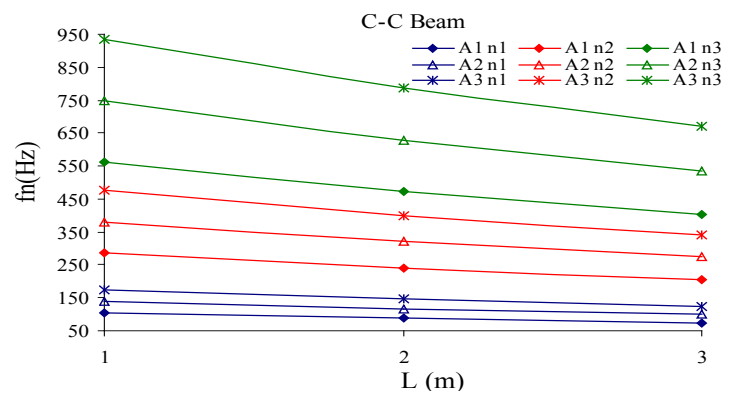

a)

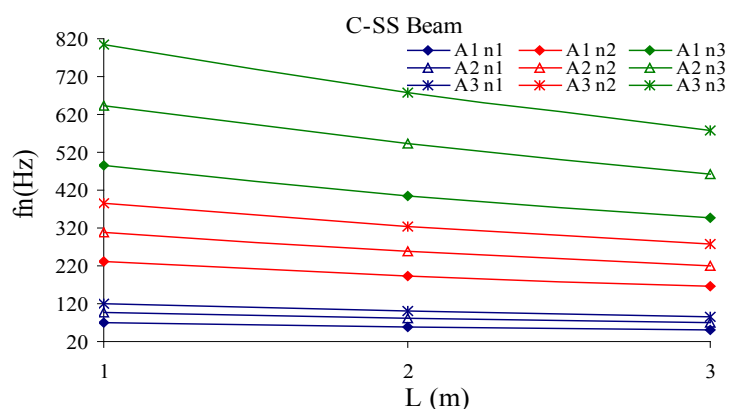

c)

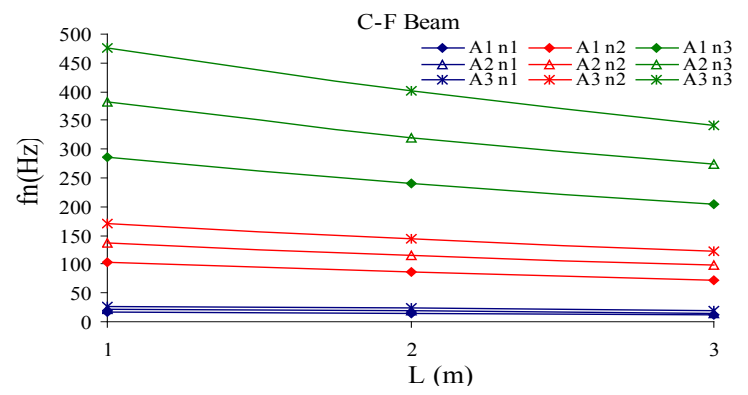

b)

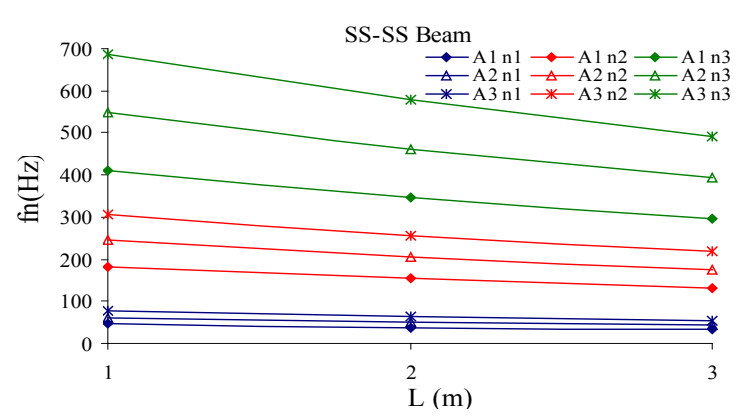

d)

Figure 4. Variations of the natural frequencies, $f_{n}(H z)$, of square cross-sectioned aluminum beams versus the length, $\mathrm{L}$ (m) $\left(E=70 \times 10^{9} \mathrm{~N} / \mathrm{m}^{2} ; \rho=2700 \mathrm{~kg} / \mathrm{m}^{3}\right)$

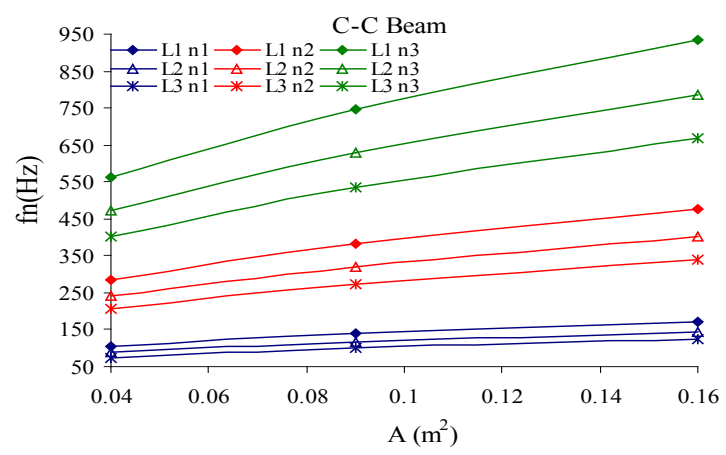

a)

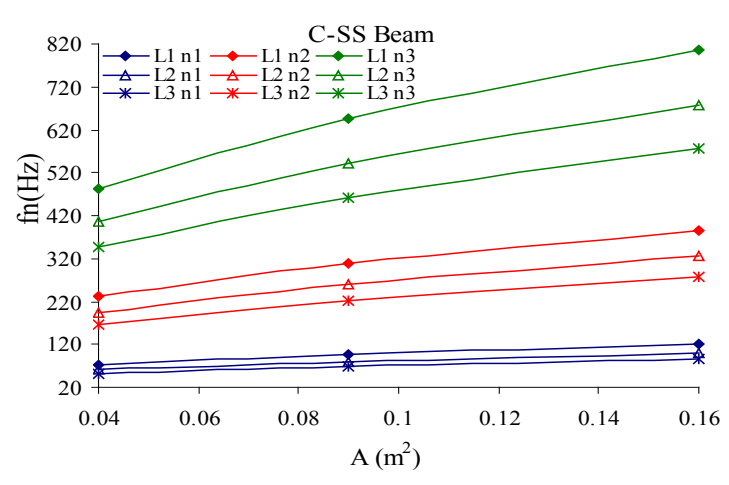

c)

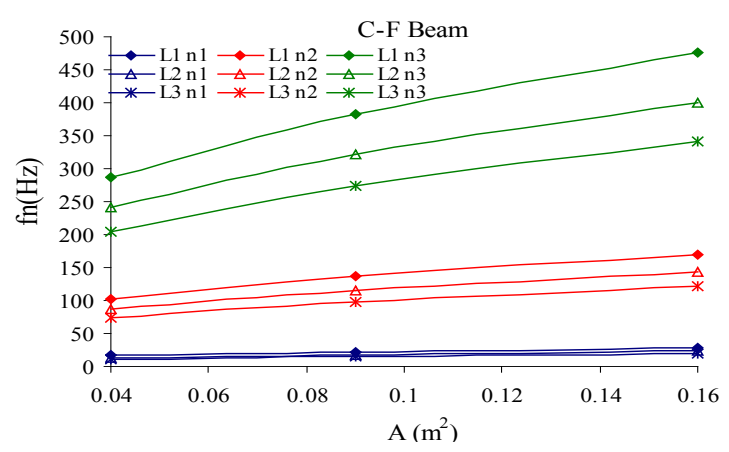

b)

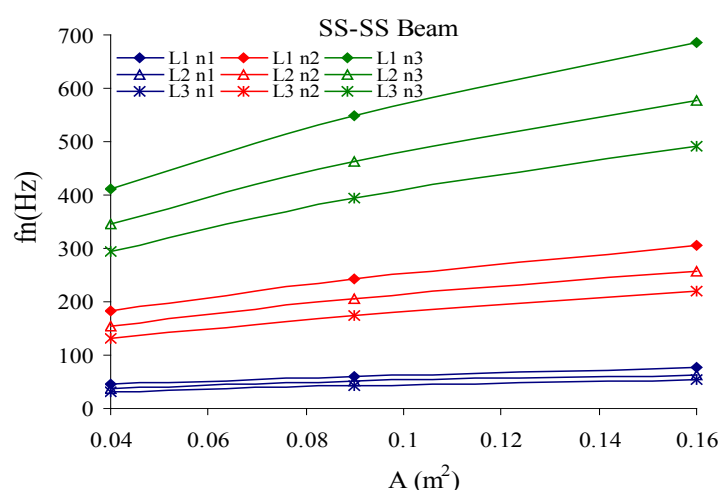

d)

Figure 5. Variations of the natural frequencies of square cross-sectioned aluminum beams versus the cross sectional area, A $\left(\mathrm{m}^{2}\right)$ $\left(E=70 \times 10^{9} \mathrm{~N} / \mathrm{m}^{2} ; \rho=2700 \mathrm{~kg} / \mathrm{m}^{3}\right)$ 


\section{Conclusions}

In this study, the free vibration of square cross-sectioned aluminum beams is investigated analytically and numerically under four different boundary conditions. Analytical solution is carried out using Euler-Bernoulli beam theory, in which material is assumed Solutions including the effects of the geometric characteristics, i.e., length and cross sectional area, and boundary conditions are obtained and discussed for the natural frequencies of the first three modes.

The following results were obtained:

(1) The natural frequencies increase with the increase in mode number.

(2) The change in mode numbers has the largest effect on the natural frequency under $\mathrm{C}-\mathrm{F}$ boundary conditions and the smallest effect under C-C boundary conditions.

(3) The beam has the highest natural frequencies under $\mathrm{C}-\mathrm{C}$ boundary conditions and the lowest frequencies under $\mathrm{C}-\mathrm{F}$ boundary conditions.

(4) The effect of the type of the boundary condition decreases with increasing mode number.

(5) The natural frequencies of the beam decrease with increasing length.

(6) The change in length of the beam has a constant effect on its natural frequencies for various boundary conditions and cross sectional areas.

(7) The natural frequencies of the beam increase with increasing cross sectional area.

(8) The change in cross sectional area of the beam has a constant effect on the natural frequencies for various boundary conditions and lengths.

\section{REFERENCES}

[1] L.H. Donnel, Beams Plates and Shells. Engineering Societies Monographs McGrawHill., 1976.

[2] J.M. Gere, S.P. Timoshenko, Mechanics of Materials. PWS Publishing Company, 1997.

[3] W.T. Thomson, Theory of Vibration with Applications. 2nd ed., Prentice Hall, 1981.

[4] L. Meirovitch, Fundamentals of Vibrations. International Edition, McGraw-Hill, 2001.

[5] A.W. Leissa, M.S Qatu, Vibration of Continuous Systems. McGraw Hill, 2011.

[6] E. Magrab, Vibrations of Elastic Systems: With Applications to MEMS and NEMS Vol. 184 Berlin: Springer, 2012.

[7] J.W.S. Rayleigh, Theory of Sound. Vol. $11^{\text {st }}$ ed., 1877.

[8] S.P. Timoshenko, On the transverse vibrations of bars of uniform cross-section. Philosophical Magazine p.125, 1922.
[9] S.P. Timoshenko, Vibration Problems in Engineering. D. Van Nostrand, 1928.

[10] J.P. Den Hartog, Mechanical Vibrations. McGraw-Hill, 1956.

[11] L. Meirovitch, Analytical Methods in Vibrations. Macmillan Publications Co., Inc., 1967.

[12] K.R Chun, Free vibration of a beam with one end spring-hinged and the other free, Journal of Applied Mechanics, 39, 1154-1155, 1972.

[13] D.J. Gorman, Free Vibration Analysis of Beams and Shafts, Wiley, New York, 1975.

[14] S.Y. Lee, H.Y. Ke, Free vibrations of a non-uniform beam with general elastically restrained boundary conditions, Journal of Sound and Vibration, 136, 425-437, 1990.

[15] S.S. Rao, Mechanical Vibrations, $3^{\text {rd }}$ edition. Reading, MA, Addison-Wesley Publishing Company, 1995.

[16] W.L. Li, Free Vibrations of beams with general boundary conditions, Journal of Sound and Vibration, 237, 709-772, 2000 .

[17] H.K. Kim, M.S. Kim, Vibration of beams with generally restrained boundary conditions using Fourier series. Journal of Sound and Vibration, 245, 771-784, 2001.

[18] S. Naguleswaran, Transverse vibration of an Euler-Bernoulli uniform beam on up to five resilient supports including ends, Journal of Sound and Vibration, 261, 372-384, 2003.

[19] M. Simsek, Free vibration analysis of beams subjected to axial load under various boundary conditions. Sigma Journal of Engineering and Natural Sciences, 3, 1-10, 2005.

[20] M.C. Ece, M. Aydogdu, V. Taskin, Vibration of a variable cross-section beam, Mechanics Research Communications, 34,78-84, 2007.

[21] T. Irvine, Bending Frequencies of Beams, Rod, and Pipes. Revision M, Vibrationdata, 2010.

[22] S.B. Coşkun, M.T. Atay, B. Ozturk, Transverse Vibration Analysis of Euler-Bernoulli Beams Using Analytical Approximate Techniques, Advances in Vibration Analysis Research, Chapter 1, Intech, 2011.

[23] J. Lee, Free vibration analysis of beams with non-ideal clamped boundary conditions, Journal of Mechanical Science and Technology, 27, 297-303, 2013.

[24] Z. Liu, Y. Yin, F. Wang, Y. Zhao, L. Cai, Study on modified differential transform method for free vibration analysis of uniform Euler-Bernoulli beam. Structural Engineering and Mechanics 48: 697-709, 2013.

[25] A. Prokic, M. Besevic, D. Lukic, A numerical method for free vibration analysis of beams, Latin American Journal of Solids and Structures, 11: 1432-1444, 2014.

[26] T. Irvine, Application of the Newton-Raphson Method to vibration problems, Revision E, Vibrationdata, 2010.

[27] ANSYS ${ }^{\circledR}$ Academic Research, Release 14.0.

[28] C. Xiaolin. Y. Liu, Finite Element Modeling and Simulation with ANSYS Workbench, CRC Press, 2014. 